\title{
Consequências no desenvolvimento da criança e adolescente vítima de violência intrafamiliar
}

\author{
Consequences on the development of children and adolescents who are victims of domestic violence
}

Consecuencias en el desarrollo de niños,niñas y adolescentes víctimas de violencia intrafamiliar

\section{Lara Luiza Lemos Machado Hingel ${ }^{*}$, Alessandra da Silva Souza ${ }^{2}$, Thiago Augusto Soares Monteiro da Silva ${ }^{3}$, Lília Marques Simões Rodrigues ${ }^{4}$, Jannaina Sther Leite Godinho Silva ${ }^{5}$, Vinícius Marins Carraro $^{6}$ \\ Como citar esse artigo. Hingel, LLLM; Souza, AS; Da Silva, TASM; Rodrigues, \\ Resumo} LMS; Silva, JSLG; Carraro, VM. Consequências no desenvolvimento da criança e adolescente vítima de violência intrafamiliar. Revista Pró-UniverSUS. 2021 Jul./Dez.; 12 (2)SUPLEMENTO: $102-106$

A violência é um problema de saúde pública e tem maiores agravos quando acontece durante a infância, podendo provocar consequências no amadurecimento da criança, fazendo com que a mesma possa desenvolver problemas durante a vida adulta. A violência contra criança começou a ganhar relevância com a implantação do Estatuto da criança e do adolescente nos anos 90 , onde o mesmo tem o objetivo de proteger integralmente a criança e o adolescente. Até pouco tempo, a violência contra criança era considerada como problema familiar sendo utilizado como um método de educar a criança. Com isso, o presente trabalho tem por objetivo identificar quais as principais consequências no desenvolvimento da criança e adolescente que foi vítima de violência intrafamiliar. Trata-se de uma pesquisa reflexiva, com abordagem qualitativa. Os critérios de inclusão e exclusão para a seleção da pesquisa foi estar disponível na íntegra em lingua portuguesa, entre os anos de 2014 a 2020. Quando a violência é praticada por um membro da família, a criança tem a crença de proteção familiar rompida, gerando distúrbios de julgamentos e na habilidade de ter relações nas quais o amor, carinho e proteção estão envolvidos. O enfermeiro é um profissional importante para o enfrentamento da violência contra criança e adolescente. Além de notificar para as autoridades, os enfermeiros podem estar vindo a investigar os casos através de visitas domiciliares no caso de enfermeiros da atenção básica. Finalizando esse estudo, é mais do que evidente a importância da capacitação de todos os profissionais da saúde tanto no âmbito hospitalar quanto na atenção básica, os profissionais enquanto capacitados tendem a ter um olhar mais holistico para a população infantojuvenil.

Palavras-chave: Criança e adolescente; Enfermagem; Intrafamiliar; Violência.

\begin{abstract}
Violence is a public health problem and it is more serious when it occurs during childhood, which can cause consequences for the child's maturation, causing the child to develop problems during adulthood. Violence against children began to gain relevance with the implementation of the Child and Adolescent Statute in the 1990s, where it aims to fully protect children and adolescents. Violence against children until recently was considered a family problem and was used as a method of educating the child. Thus, this study aims to identify the main consequences for the development of children and adolescents who have been victims of domestic violence. It is a reflective research, with a qualitative approach. The inclusion and exclusion criteria for the selection of the research was to be available in full in Portuguese, between the years 2014 to 2020. When violence is committed by a family member, the child has a broken family protection belief, generating disorders of judgment and the ability to have relationships in which love, care and protection are involved. The nurse is an important professional to face violence against children and adolescents. In addition to notifying the authorities, nurses may be investigating cases through home visits in the case of primary care nurses. At the end of this study, it is more than evident the importance of training for all health professionals both in the hospital and in primary care, while trained professionals tend to have a more holistic view of the children and youth population.
\end{abstract}

Keywords: Child and teenager; Intra-family; Nursing; Violence.

Afiliação dos autores: 'Graduanda de Enfermagem, Universidade de Vassouras, Vassouras. RJ, Brasil. ORCID: https://orcid.org/0000-0002-3259-0434.

${ }^{2}$ Mestre em Enfermagem. Professora Adjunta da Universidade de Vassouras, Vassouras, RJ, Brasil. ORCID: https://orcid org/0000-0002-9009-9774.

${ }^{3}$ Doutor em Enfermagem pela Escola de Enfermagem Anna Nery da Universidade Federal do Rio de Janeiro. Professor Adjunto do curso de Enfermagem da Universidade de Vassouras, Vassouras, RJ, Brasil. ORCID: https://orcid.org/0000-0001-6870-5101.

${ }^{4}$ Mestre em Enfermagem pela EEAAC-UFF. MBA em Administração Hospitalar, Coordenadora do Curso de Enfermagem da Universidade de Vassouras, Vassouras, RJ, Brasil. ORCID: https://orcid.org/00000003-2979-6316.

${ }^{5}$ Mestre em Enfermagem pela Universidade Federal Fluminense. Especialista em Neonatologia pelo IFF/FIOCRUZ. Especialista em Fitoterapia, Suplementação de Alimentos Funcionais na Prática Clínica pelo CUVR. Especializando em Acupuntura pelo Incisa/IMAN. Professora do curso de Enfermagem da Universidade de Vassouras, Vassouras, RJ, Brasil. ORCID: https://orcid.org/0000-0002-8308-2093. ${ }^{6} \mathrm{PhD}$ em Medicina Veterinária, Parasitologia Veterinária. Professor Adjunto dos Cursos de Enfermagem, Medicina, Medicina Veterinária e Mestrado Profissional em Ciências Ambientais pela Universidade de Vassouras, Vassouras, RJ, Brasil. ORCID: https://orcid.org/0000-0001-6746-4932

*Email de correspondencia: larahingel571@gmail.com

Recebido em: 21/01/21. Aceito em: 30/04/21 


\section{Resumen}

La violencia es un problema de salud pública y es más grave cuando ocurre durante la infancia, lo que puede tener consecuencias en la maduración del niño, provocando que el niño desarrolle problemas durante la edad adulta. La violencia contra la niñez comenzó a cobrar relevancia con la implementación del Estatuto de la Niñez y la Adolescencia en la década de 1990, donde tiene como objetivo proteger plenamente a la niñez y adolescencia. La violencia contra los niños hasta hace poco se consideraba un problema familiar y se utilizaba como método para educar al niño. Así, este estudio tiene como objetivo identificar las principales consecuencias para el desarrollo de niños, niñas y adolescentes víctimas de violencia intrafamiliar. Es una investigación reflexiva, con enfoque cualitativo. Los criterios de inclusión y exclusión para la selección de la investigación debían estar disponibles en su totalidad en portugués, entre los años 2014 a 2020. Cuando la violencia es cometida por un miembro de la familia, el niño tiene una creencia de protección familiar rota, generando trastornos del juicio y la capacidad de tener relaciones en las que intervienen el amor, el cuidado y la protección. La enfermera es un profesional importante para enfrentar la violencia contra la niñez y la adolescencia. Además de notificar a las autoridades, las enfermeras pueden estar investigando casos a través de visitas domiciliarias en el caso de las enfermeras de atención primaria. Al final de este estudio, es más que evidente la importancia de la formación de todos los profesionales de la salud tanto en el hospital como en la atención primaria, mientras que los profesionales formados tienden a tener una visión más holística de la población infantil y juvenil.

Palabras clave: Enfermería; Intrafamiliar; Niño y adolescente; Violencia.

\section{Introdução}

A violência é um problema de saúde pública e tem maiores agravos quando acontece durante a infância, podendo provocar consequências no amadurecimento da criança, fazendo com que a mesma possa desenvolver problemas durante a vida adulta. ${ }^{1}$ Segundo a Organização Mundial da Saúde ${ }^{2}$ a violência pode ser definida como uso da força física ou do poder, real ou em ameaça, contra si próprio, contra outra pessoa, ou contra um grupo ou uma comunidade. Dentre os tipos de violência infantil, a Organização Mundial da Saúde ${ }^{1}$ classifica a violência contra criança em quatro tipos: Abuso sexual, emocional ou psicológico, físico e negligência.

A violência contra criança começou a ganhar relevância com a implantação do Estatuto da criança e do adolescente nos anos 90 , que tem o objetivo de proteger integralmente a criança e o adolescente. $\mathrm{O}$ artigo sétimo do estatuto da criança e do adolescente ${ }^{3}$ prevê que a criança e o adolescente têm direito a proteção à vida e a saúde.

A associação Brasileira multiprofissional de proteção à infância e adolescência ${ }^{4}$ publicou uma estatística sobre 1.169 casos de violência doméstica ligada a crianças e adolescentes em que 93,5\% dos casos o agressor era um familiar. A cada ano, três de dez milhões de crianças sofrem todos os tipos de violência, além disso, o agressor ligado a criança, em sua maioria, reside no mesmo domicílio onde deveria ser um lugar de proteção, carinho e atenção para o jovem, tornandose um ambiente onde a criança não se sente acolhida. Quando a violência é praticada por um membro da família, a crença de que o ambiente familiar é um lugar seguro para a criança é rompido, gerando, assim, distúrbios no julgamento e na habilidade de ter relações nas quais o amor, carinho e proteção estão envolvidos. A violência doméstica, mesmo não deixando marcas físicas, acaba deixando a criança vulnerável em vários aspectos.
O jovem que foi vítima, muitas vezes acaba se isolando e tende a ter o lado afetivo abalado, podendo tornar-se um adulto incapaz de se relacionar afetivamente com outra pessoa e incapaz de ter um relacionamento sadio com o restante dos familiares. Quanto ao gênero, nas faixas mais tardias da adolescência, as meninas foram as que mais sofreram abusos em relação aos meninos. A violência sexual e psicológica tem mais chances de ocorrer nas meninas enquanto a violência física e a negligência mais chances de ocorrer nos meninos. ${ }^{5}$

A violência contra criança, até pouco tempo, era considerado como problema familiar, sendo utilizado como um método de educar a criança. Em 2011, 14.625 casos foram notificados, e a maior parte das agressões ocorreu dentro da residência da criança. ${ }^{6}$

Diante desse panorama, o presente trabalho tem por objetivo identificar quais as principais consequências no desenvolvimento da criança e adolescente que foi vítima de violência intrafamiliar através de uma pesquisa reflexiva, com abordagem qualitativa

\section{Metodologia}

Trata-se de uma pesquisa reflexiva, na qual o pesquisador deve constantemente analisar suas ações e suas regras no processo de pesquisa e sujeitá-las ao mesmo exame atencioso que o restante dos dados. ${ }^{7}$

Com abordagem qualitativa, que, segundo a literatura, significa que é o que se aplica ao estudo da história, relações e interpretações, crenças, opiniões e percepções do ser humano, permite desvendar os processos sociais para análises de discursos e documentos ${ }^{8}$.

O levantamento foi composto por artigos publicados em periódicos a partir de algumas bases de dados como: SCIELO, BIREME, LILACS, no período de março a dezembro de 2020, foram selecionados 
artigos dentro do Estatuto da Criança e do Adolescente, dados dentro do Anuário Brasileiro de Segurança Pública e definições dentro do Ministério dos Direitos Humanos. Os critérios de inclusão e exclusão para a seleção da pesquisa foram disponibilidade na íntegra em lingua portuguesa, e publicações entre os anos de 2014 a 2020. Foram selecionados 38 instrumentos para construção do presente trabalho, como artigos, leis, anuários e manuais. 23 instrumentos dentre os 38 fazem parte da estruturação do presente artigo e 15 foram excluídos por não apresentarem elementos relevantes para a estruturação do mesmo.

Os descritores utilizados para realização das buscas foram: Violência; Intrafamiliar; Criança e Adolescente; Enfermagem.

\section{Resultados e Discussão}

Segundo a Organização Mundial da Saúde ${ }^{2}$, violência pode ser definida como o uso da força física ou do poder, real ou em ameaça, contra si próprio, contra outra pessoa, ou contra um grupo ou uma comunidade. A Organização Mundial da Saúde $^{9}$ caracteriza as formas de violência que envolve crianças e adolescente como quaisquer meios de maus-tratos que possa ocasionar danos a saúde da criança, sobrevivência, desenvolvimento ou dignidade no contexto de uma relação de responsabilidade, confiança ou poder.

$\mathrm{O}$ Estatuto da Criança e Adolescente ${ }^{10}$ refere no seu artigo $5^{\circ}$ que nenhuma criança ou adolescente deve ser objeto de qualquer forma de negligência, discriminação, exploração, violência, crueldade e opressão punido na forma da lei qualquer atentado por ação ou omissão aos seus direitos fundamentais.

Segundo o Ministério dos Direitos Humanos ${ }^{11}$, a violência intrafamiliar é toda ação ou omissão que prejudique o bem-estar, a integridade física, psicológica ou a liberdade e o direito ao pleno desenvolvimento de outro membro familiar. Já a violência doméstica se difere da intrafamiliar podendo ser cometida por outras pessoas que não fazem parte do grupo familiar da criança mas que convive no mesmo âmbito.

Segundo o referido artigo $^{12}$, a violência é tão antiga quanto todas as sociedades. A violência que se configura no Brasil, atualmente, é fruto do processo histórico e tem suas origens na colonização. Em suma, a violência pode ser caracterizada de forma física ou simbólica, e esteve presente em todos os períodos históricos, abrangendo todas as dimensões sociais, até mesmo as práticas do cotidiano. Com o processo de maior conexão entre as sociedades, a violência se intensificou pelo desejo de dominação.

No Brasil, a cultura de agredir a criança como método de educação teve forte influência religiosa na colonização, quando os padres utilizavam castigos físicos como meio de "educar". Nas sociedades antes de Cristo, as crianças só obtinham o direito à vida caso os pais aceitassem assumi-las como seus filhos, mesmo assim, as crianças eram submetidas a rituais como, por exemplo, serem colocadas dentro de um rio gelado. Caso sobrevivesse, a criança estava apta a viver. ${ }^{13}$

A violência doméstica infantil tem crescido e alcançado grandes proporções, tornando-se um problema de saúde pública. É importante ressaltar que a experiência de violência na infância pode influenciar nas conexões neurais do cérebro causando mudanças capazes de aumentar a vulnerabilidade e causar transtornos psíquicos em outras fases da vida. Sabese que a violência psicológica pode levar a agravos mentais, tais como: ansiedade, depressão, hiperatividade, agressividade e podendo levar a criança/adolescente a pensamentos e práticas suicídas.

Algumas consequências do abuso sexual são de especial importância para compreendermos a real dimensão dos impactos físicos, emocionais e psicossociais causados pelo abuso:

[...] Ter vivido um trauma físico e psicológico faz com que a vítima questione sua capacidade de defender-se. Ela aprende a odiar o seu corpo porque ele a faz lembrar de más experiências. Ela tem respostas dissociadas, apresenta dificuldade de intimidade e é emocionalmente distante. Ela aprende que não pode controlar seu corpo e que outra pessoa pode tocá-la sem o seu consentimento. Ela não confia na sua memória, nos seus pensamentos e no seu senso de realidade. Essas consequências afetam não só a vítima, mas também a sociedade em geral porque uma criança traumatizada torna-se eventualmente um adulto que pode adotar comportamentos agressivos ou passivos para resolver as situações de estresse ${ }^{14}$.

Além disso, crianças e adolescentes que foram vítimas de violência sexual, podem apresentar danos físicos, como: lesões nas genitais, lesões anorretais, hematomas pelo corpo, infecção sexualmente transmissível e, no caso das meninas, gravidez. No ano de 2019, segundo o Anuário Brasileiro de Segurança Pública, ${ }^{15} 57,9 \%$ das vítimas de violência sexual tinham no máximo 13 anos de idade. Além dos danos físicos, os danos psicológicos são imensos, como: depressão, ansiedade e distúrbio do sono.

Quando a violência é praticada por um membro da família, a criança tem a crença de proteção familiar rompida, gerando distúrbios de julgamentos e na habilidade de ter relações nas quais o amor, carinho e proteção estão envolvidos. A violência doméstica, mesmo não deixando marcas físicas, acaba deixando a criança vulnerável em vários aspectos, pois é durante a infância em que a criança aprende noções de certo e errado e capacidade de solucionar problemas. Quando a criança é violentada, ela tende eventualmente a tornar-se um adulto agressivo, pois toma esse modelo agressivo que vivenciou durante a infância como algo natural. O menor que foi vítima de violência doméstica, 
muitas vezes, acaba isolando-se e tende a ter o lado afetivo abalado, podendo tornar-se incapaz de ter um relacionamento sadio com o restante dos familiares.

Em 2019, o registro apresentado pelo Anuário Brasileiro de Segurança Pública ${ }^{15}$ mostrou que 64,6\% dos casos de violência ocorreram dentro da residência da criança. Destrinchando esse número, é importante informar qual vínculo o jovem tem com o agressor. Os dados disponíveis no anuário mostram que 39\% dos casos de violência sexual/violência física foram cometidos pelo padrasto da vítima. A violência contra crianças e adolescentes é uma das principais causas de morbimortalidade na faixa etária de cinco a 19 anos, sendo responsabilidade do profissional de saúde notificar as ocorrências de tal violência. ${ }^{16}$

Ao chegar casos confirmados ou suspeitos de violência infantil em unidades ou hospitais, um dos primeiros profissionais a ter contato com a criança é o enfermeiro. O profissional, de modo geral, tem papel importante no reconhecimento da violência que acomete crianças e adolescentes. ${ }^{17}$

A suspeita de violência geralmente surge durante a anamnese com o jovem, durante a qual o profissional deve observar todos os aspectos, tanto emocionais quanto os sinais comportamentais que a criança possa demonstrar durante a entrevista. Alguns sinais comportamentais observados são: medo de uma pessoa específica ou pânico quando são deixados sozinhos.

Durante o exame físico, alguns sinais corporais podem ser observados, tais como: dor, inchaço, sangramento nas áreas da vagina e ânus, hematomas e traumas. É importante estar preparado e ter os conhecimentos necessários para enfrentar situações como a violência. Ao conversar com os responsáveis da criança/adolescente, é importante o enfermeiro estar atento a relatos discordantes ente o responsável e a criança, e é de suma importância o enfermeiro conseguir identificar precocemente os casos encaminhados, conseguindo criar um vínculo com a criança, possibilitando, assim, que ela tenha confiança no profissional de saúde e consiga se expressar sem sentir medo de sofrer novamente a violência denunciada.

Muitas vezes, os profissionais não conseguem identificar outros tipos de violência por ela também envolver aspectos biopsicossociais que vão além da agressão física. Por isso, é importante continuar se capacitando para conseguir atender casos de violência quando necessário. Outra forma importante de conseguir levar casos suspeitos a serem investigados é através da notificação. O Ministério da Saúde, ${ }^{18}$ através da Portaria 104, prevê que é obrigatório notificar novos casos de doenças e agravos, incluindo a violência.

Em casos de suspeita de violência contra crianças e adolescentes, deve-se notificar não só a vigilância sanitária como também o conselho tutelar. $\mathrm{O}$ artigo 13 do ECA $^{19}$ esclarece que casos de suspeitos ou confirmados de castigos físicos, tratamento cruel ou degradante e de maus-tratos contra criança e adolescentes deverão obrigatoriamente serem notificados ao Conselho Tutelar da cidade de residência, sem nenhum prejuízo de outras previdências legais.

O profissional deve lembrar-se que notificar uma suspeita não significa que ele está denunciando os responsáveis. De acordo com o $\mathrm{ECA}^{20}{ }^{20}$ a pessoa que presenciar alguma prática de violência contra uma criança ou adolescente e não denunciar ao órgão responsável, está sujeita a receber punições vigentes no código penal do país. Seguindo essa linha, de acordo com o ECA20, seu artigo 245 afirma que o profissional de saúde, professor ou responsável pela unidade de saúde que não notificar a violência, poderá ser punido através de uma multa de três a vinte salários mínimos de referência, sendo o valor duplicado em caso de reincidência da violência.

A notificação de violência segue o mesmo fluxograma de qualquer notificação compulsória, devendo iniciar na unidade de saúde notificadora e ser enviada para os órgãos competentes para que as providências legais e cabiveis sejam tomadas.

Existem outras leis que protegem as crianças e adolescentes, como, por exemplo, a lei da palmada, ${ }^{21}$ que foi sancionada em 2014 e que estabelece o direito da criança e do adolescente de serem educados sem receber castigos físicos ou tratamentos cruéis, e a lei 12. 852 , de 5 de agosto de $2013,{ }^{22}$ que dispõe sobre os direitos dos jovens. O Estatuto prevê como direito da juventude: o direito à cidadania, à participação social e política e à representação juvenil. Direito à educação; direito à profissionalização, trabalho e renda; direito à diversidade e igualdade; direito à saúde; direito à cultura; direito à comunicação e liberdade de expressão; direito ao desporto e ao lazer; direito à segurança pública e ao acesso à justiça.

O enfermeiro é um profissional importante para o enfrentamento da violência contra criança e adolescente. Além de notificar para as autoridades, os enfermeiros podem estar vindo a investigar os casos através de visitas domiciliares no caso de enfermeiros da atenção básica, podendo observar o ambiente em que a criança/adolescente vive, os moradores da residência e como essa criança se comporta perto dos mesmos. Infelizmente, muitos profissionais sentem-se inseguros ao se depararem com uma problemática como a violência infantil. Tendem a sentir medo por estarem expostos ao agressor e receio que a agressão contra a criança se repita, impedindo, assim, que uma assistência mais direta fosse prestada, impossibilitando a prevenção da reincidência da violência. ${ }^{23}$ 


\section{Conclusão}

Pelos dados levantados no presente estudo, pôdese identificar as consequências que a violência infantil pode trazer para o desenvolvimento biopssicosocial da criança, também nos fazendo refletir quanto a assistência prestada à população infantil que foi vitimizada.

A falta de capacitação dos profissionais de saúde é apontada como uma das maiores dificuldades no enfrentamento contra a violência intrafamiliar, fazendo com que muitos casos passem por despercebidos durante uma avaliação. Então, finalizando esse estudo, é mais do que evidente a importância da capacitação de todos os profissionais da saúde tanto no âmbito hospitalar quanto na atenção básica, os profissionais enquanto capacitados tendem a ter um olhar mais holístico para a população infanto-juvenil, garantindo, assim, o seu direito de proteção à vida e à saúde que está vigente no artigo sétimo do Estatuto da Criança e do Adolescente.

Vale ressaltar que, mesmo existindo vários dispositivos legais que protegem a criança e o adolescente, a violência infanto-juvenil ainda perdura e foi demonstrada através dos números evidenciados no presente artigo.

Concluímos que o assunto deve ser cada vez mais discutido durante a graduação de enfermagem para que o futuro profissional tenha competências e habilidades para lidar com a situação, sendo capaz de intervir, resgatando os valores da família e dos atores envolvidos num contexto violento através da promoção e prevenção, traçando metas e medidas de educação em saúde e de forma continuada, estimulando o desenvolvimento das políticas públicas de enfrentamento à violência da criança e do adolescente em âmbito nacional.

Após o término do levantamento dos dados, considera-se que o objetivo de identificar quais as principais consequências no desenvolvimento da criança e adolescente que foi vítima de violência intrafamiliar foi atingido, contribuindo, desta forma, significativamente, para a prática profissional da enfermagem.

\section{Referências}

1. Nunes AJ, Sales MCV. Violência contra crianças no cenário brasileiro. Ciênc. Saúde coletiva. 2016; 21(3): 871-880

2. Krug EG, Dahlberg LL, Mercy JA, Zwi AB, Lozano R. Relatório Mundial sobre violência e saúde. Genebra: Organização Mundial da Saúde, 2002

3. Brasil. Lei 8069/90, de 13 de julho de 1990. Dispõe sobre o Estatuto da Criança e Adolescente e dá outras providêncas.[Internet]. [acesso em: 10 de dez. 2020]. Disponível em: http://www.planalto.gov.br/ccivil_03/leis/ 18069.htm

4. Frota MA, Martins HFC, Gonçalves LMP, Filho OAS, Casimiro CF. Percepção da criança acerca da agressão física intrafamiliar. Ciênc. Cuid. Saúde. 2011; 10(1): 44-50

5. Rates SMM, De melo EM, Mascarenhas MDM, Malta DC. Violência infantil: uma análise das notificações compulsórias, Brasil 2011. Ciênc.
Saúde coletiva. 2015;20(3): 655-665

6. Dos reis ERL, De souza SJP, Migoto MT, Weigert SP. Dificuldades dos profissionais de saúde em identificar e notificar a violência infantil. Rev. Gestão. Saúde. 2017; 10(Supl 1): 63-70

7. De oliveira SR, Piccinini VC. Validade e reflexividade na pesquisa qualitativa. Cad. EBAPE. 2009; 7(1): 89-98

8. Minayo MCS. Pesquisa social teoria, método e criatividade. $21^{\mathrm{a}}$ Edição. Rio de Janeiro: Vozes, 2002

9. Egry EY, Apostólico MR, Morais TCP, Lisboa CCR. Enfrentar a violência infantil na Atenção Básica: como os profissionais percebem?. Rev. Bras. Enferm. 2017; 70(1): 119-125

10. Brasil. Artigo $5^{\circ}$ da Lei $n^{\circ} 8069 / 90$, de 13 de julho de 1990, Dispõe sobre o Estatuto da Criança e Adolescente e dá outras providêncas.[Internet] [acesso em: 10 de dez. 2020] Disponível em: http://www.planalto.gov.br/ ccivil 03/leis/18069.htm\#: :text=Art. $\% 205 \%$ C2\%BA\%20Nenhuma $\% 20$ crian $\overline{0}$ C3\% A 7a $\% 20$ ou,omiss $\%$ C3\%A3o\%2C\%20aos $\% 20$ seus $\% 20$ direitos $\% 20$ fundamentais.

11. Ministério dos Direitos Humanos. Violência contra crianças e adolescentes: Análise de Cenários e Propostas de Políticas Públicas: 2018. Brasília, 2018

12. Bernaski J, Sochodolak H. História da violência, cotidiano e vida social. In: XV Encontro Regional de História; 26-29 jul 2016; Curitiba. Curitiba (PR): UFPR; 2016. 1-13

13. Oliveira RV, Pais LG. A Origem dos Maus-Tratos: Revisão Sobre a Evolução Histórica das Perceções de Crianças e Maus-Tratos. Psychology, Community \& Health. 2014;3(1): 36-49

14. Antony S, De Almeida EM. Vítimas de Violência sexual intrafamiliar: uma abordagem gestáltica. Rev. Nufen. 2018; 10(2): 184-201

15. Fórum Brasileiro de Segurança Pública. Anuário Brasileiro de Segurança Pública: 2020. São Paulo, 2020.

16. Costa MCO, De Carvalho RC, Bárbara JFRS, Santos CAST, Gomes WA, De Souza HL.O perfil da violência contra crianças e adolescentes, segundo registros de Conselhos Tutelares: vítimas, agressores e manifestações de violência. Ciênc. Saúde coletiva. 2007;12(5): 1129-1141

17. de Paula, ACF; de CARVALHO, BO; Fróes, DTC; Ferreira, GSF; Pinto, RA; Santa-Rosa, TTA. Reconhecimento e conduta de cirurgiõesdentistas diante de maus-tratos em crianças e adolescentes. Revista PróUniverSus. 2019 Jan/Jun.; 10(1): 137-144

18. Garbin CAS, Dias IA, Rovida TAS, Garbin AJÍ. Desafios do profissional de saúde na notificação da violência: obrigatoriedade, efetivação e encaminhamento. Ciênc. Saúde coletiva. 2015; 20(6): 1879-1890

19. Brasil. Artigo 13 da Lei $n^{\circ} 8069$ de 13 de julho 1990. Dispõe sobre o Estatuto da Criança e Adolescente e dá outras providêncas.[Internet]. [acesso em: 10 de dez. 2020]. Disponível em: https://www.jusbrasil.com.br/ topicos/10618641/artigo-13-da-lei-n-8069-de-13-de-julho-de-1990/artigos

20. Brasil. Artigo 245 da Lei ${ }^{\circ} 8069$ de 13 de julho de 1990. Dispõe sobre o Estatuto da Criança e Adolescente e dá outras providências.[Internet]. [acesso em: 10 de dez. 2020]. Disponível em: https://presrepublica.jusbrasil. com.br/legislacao/91764/estatuto-da-crianca-e-do-adolescente-lei-806990\#art-245

21. Pinheiro BK, Iwata MA. Violência Intrafamiliar contra a criança: Intervenção de enfermeiros da estratégia saúde da familia. Rev. Da Rede de Enferm. Do Nordeste. 2012; 13(2): 354-364

22. Brasil. Lei $\mathrm{n}^{\circ} 13.010$ de 26 de junho de 2014.[Internet].[acesso em: 10 de dez. 2020]. Disponível em: http://www.planalto.gov.br/ccivil_03/_ ato2011-2014/2014/lei/113010.htm

23. Brasil. Lei ${ }^{\circ} 12.852$ de 05 de agosto de 2013. Dispõe sobre os direitos dos jovens, os princípios e diretrizes das políticas públicas de juventude e o Sistema Nacional de Juventude. [Internet]. [acesso em: 10 de dez. 2020]. Disponível em: http://www.planalto.gov.br/ccivil_03/_Ato2011-2014/2013/ Lei/L12852.htm 